\title{
PENGARUH MOTIVASI DAN DISIPLIN KERJA TERHADAP KINERJA PNS PADA DINAS KOPERASI USAHA KECIL DAN MENENGAH (UKM) PROVINSI SUMATERA SELATAN
}

\author{
Akila *)
}

\begin{abstract}
ABSTRAK
Tujuan penelitian ini adalah untuk mengetahui pengaruh motivasi dan disiplin kerja terhadap kinerja PNS pada Dinas Koperasi Usaha Kecil dan Menengah (UKM) Provinsi Sumatera Selatan. Metode penelitian adalah metode deskriptif kuantitatif dan hipotesis untuk menguji mengenai pengaruh motivasi dan disiplin kerja terhadap kinerja PNS pada Dinas Koperasi Usaha Kecil dan Menengah (UKM) Provinsi Sumatera Selatan. Populasi dalam penelitian ini adalah seluruh pegawai (PNS) pada Dinas Koperasi Usaha Kecil Dan Menengah (UKM) Provinsi Sumatera Selatan yang berjumlah 92 pegawai dan sekaligus diambil sebagai sampel.

Hasil Penelitian menunjukan bahwa 1) Motivasi berpengaruh secara signifikan terhadap kinerja PNS. 2) Disiplin kerja secara signifikan berpengaruh terhadap kinerja PNS. 3) Motivasi dan disiplin kerja secara bersama-sama berpengaruh signifikan terhadap kinerja PNS.
\end{abstract}

Kata Kunci: motivasi, disiplin kerja dan kinerja PNS

\section{PENDAHULUAN}

\section{A. Latar Belakang}

Sumber daya manusia merupakan salah satu faktor produksi yang memegang peranan penting dalam upaya sebuah organisasi mencapai tujuannya. hal ini disebabkan karena SDM merupakan faktor produksi yang mampu mengelola faktor produksi lain yang dimiliki oleh organisasi. Oleh karena itu, setiap organisasi tentunya senantiasa berupaya untuk mendapatkan SDM yang memiliki keterampilan, pengetahuan, dan sikap yang baik agar faktor produksi lain yang dimiliki oleh organisasi dapat dikelola dengan baik sehingga pada akhirnya organisasi tersebut mampu mencapai tujuan secara efektif dan efisien. era globalisasi saat ini yang ditandai dengan perkembangan yang semakin cepat dalam berbagai bidang, menyebabkan persaingan yang semakin ketat. Sumber daya manusia selaku pelaku organisasi sangat penting perannya dalam pencapaian tujuan organisasi.

Motivasi sangat penting baik dari diri sendiri maupun dari atasan.
Dalam melakukan suatu pekerjaan setiap pegawai membutuhkan motivasi yang ada pada dirinya agar timbul suatu semangat atau kegairahan dalam bekerja. Ada dua rasangan motivasi yaitu dari dalam diri karyawan itu sendiri dan dari faktor luar pegawai. Setiap pegawai memiliki perbedaan motivasi pada dirinya dalam bekerja ada yang menginginkan suatu penghargaan yang diberikan oleh instansi dimana ia bekerja dan rasa puas dalam mengerjakan suatu pekerjaan yang hanya biasa dirasakan oleh dirinya sendiri.

Adapun

permasalahan mengenai pelaksanaan yang berjalan dimana beban kerja yang berlebihan, peran yang racu, tanggung jawab terhadap pekerjaan tidak dilaksanakan dengan baik, suasana lingkungan kerja yang tidak begitu nyaman, bahkan hilanganya kekompakan dalam suatu organisasi, dan tidak ada dukungan yang memadai antara satu pegawai dengan pengawai lain. Sementara itu pegawai kurang memiliki motivasi yang tinggi dan disiplin kerja dikarenakan sering tidak adanya pekerjaan yang harus dikerjakan, dan kurangnya 
fasilitas teknologi yang mendukung kinerja pegawai. Menurut hasil dan pengamatan sementara yang telah dilakukan masih banyak pegawai yang datang dan pulang tidak tepat waktu, tugas yang tidak diselesaikan tepat waktu, keluar disaat jam kerja sehingga tidak adanya untuk memotivasi diri terhadap tanggung jawabnya sehingga pegawai belum disiplin dalam bekerja.

\section{B. Rumusan Masalah}

1. Adakah Pengaruh Motivasi Terhadap Kinerja PNS di Dinas Koperasi Usaha Kecil dan Menengah (UKM) Provinsi Sumatera Selatan?

2. Adakah Pengaruh Disiplin Kerja Terhadap Kinerja PNS di Dinas Koperasi Usaha Kecil dan Menengah (UKM) Provinsi Sumatera Selatan?

3. Adakah Pengaruh Motivasi dan Disiplin Kerja Terhadap Kinerja PNS di Dinas Koperasi Usaha Kecil dan Menengah (UKM) Provinsi Sumatera Selatan?

\section{PROSEDUR PENELITIAN}

A. Ruang Lingkup Pembahasan

Agar tujuan penelitian dapat dilakukan dan dicapai, maka ada beberapa variabel yang akan dibahas dan nantinya akan biasa digunakan dalam penyelesaian yaitu:

1. Motivasi adalah dorongan yang terdapat dari dalam diri atau dari luar diri suatu individu.

2. Disiplin Kerja: Kesadaran dan kesetiaan seseorang mentaati semua peraturan instansi dan norma-norma sosial yang berlaku.

3. Kinerja pegawai: pekerjaan yang dicapai seseorang berdasarkan persyaratan-persyaratan pekerjaan.

Komponen indikator yang dihasilkan dengan jumlah pertanyaan sebanyak 10 butir pertanyaan untuk masing-masing pertanyaan memiliki lima (5) alternative dan dihitung menggunakan pad tabel skala likert.

\section{B. Populasi dan Sampel}

Populasi adalah wilayah generasi yang terdiri atas objek/subjek yang mempunyai kualitas dan karakteristik tertentu yang ditetapakan oleh peneliti. Sugiyono, (2013:115). Populasi dalam penelitian ini adalah seluruh pegawai (PNS) pada Dinas Koperasi Usaha Kecil Dan Menengah (UKM) Provinsi Sumatera Selatan yang berjumlah 92 pegawai.

Sampel adalah bagian dari jumlah dan karakteristik yang dimiliki oleh populasi tersebut. Sugiyono, (2013:116). Dalam penelitian ini menggunakan sensus, sensus adalah teknik penentuan sampel bila semua anggota populasi di gunakan sebagai sampel yaitu 92 .

\section{Metode Pengumpulan Data}

Teknik pengumpulan data dalam penelitian ini adalah dengan cara interview (wawancara), kuesioner (angket), dan observasi (pengamatan), Sugiyono (2013:401).

1. Interview (wawancara), Wawancara digunakan sebagai teknik pengumpulan data, apabila peneliti ingin melakukan studi pendahuluan untuk menemukan permasalahan yang harus diteliti. wawancara dilakukan pada pegawai Dinas Koperasi Usaha Kecil dan Menengah (UKM) Provinsi Sumatera Selatan dalam penelitian ini.

2. Kuesioner (angket), Kuesioner merupakan teknik pengumpulan data yang dilakukan dengan memberi seperangkat pertanyaan tertulis kepada respoden untuk dijawab. Penyebaran kuesioner dilakukan di Dinas Koperasi Usaha 
Kecil dan Menengah (UKM) Provinsi Sumatera Selatan dengan menjadikan pegawai sebagai objek.

3. Observasi, sebagai teknik pengumpulan data mempunyai ciri yang spesifik bila dibandingkan dengan teknik yang lain, yaitu wawancara dan kuisoner. observasi yang dilakukan adalah terhadap objek yang ada di Dinas Koperasi Usaha Kecil dan Menengah (UKM) Provinsi Sumatera Selatan.

\section{Teknik Analisis Data}

1. Analisis Regresi Linear Berganda

Menurut Sugiyono (2013:277) Analisis regresi ini bertujuan untuk mengetahui ada tidaknya suatu hubungan antara variabel $X_{1}$, dan $X_{2}$ dengan $Y$ dimana ketiga variabel tersebut motivasi dan disiplin kerja sebagai variabel bebas, dan kinerja pegawai sebagai variabel tidak bebas atau terikat. Analisis regresi ini dinyatakan dengan persamaan sebagai berikut:

$$
\mathbf{Y}^{\prime}=\mathbf{a}+\mathbf{b}_{1} \mathbf{X}_{1}+\mathbf{b}_{2} \mathbf{X}_{2}+\mathbf{e}
$$

Dimana:

$$
\begin{aligned}
& \mathrm{Y}^{\prime}=\text { Variabel Tidak } \\
& \text { Bebas/Dependent } \\
& \text { (Kinerja Pegawai) } \\
& \mathrm{X}_{1}=\text { Variabel Bebas } \\
& \text { Independent (Motivasi) } \\
& \mathrm{X}_{2}=\underset{\text { Independent }}{\text { Variabel }} \text { (Disiplin } \\
& \text { Kerja) } \\
& \mathrm{a}=\text { Bilangan Konstanta } \\
& \mathrm{b}_{1}=\text { Koefisien Regresi } \\
& \text { Motivasi } \\
& b_{2}=\text { Koefisien Regresi Disiplin } \\
& \text { Kerja } \\
& \mathrm{e}=\text { Nilai Residual }
\end{aligned}
$$

2. Analisis Koefisien korelasi berganda

Sugiyono

(2013:231)

mendefinisikan bahwa korelasi berganda merupakan angka yang menujukkan arah dan kuatnya hubungan antara dua variabel independen secara bersama-sama atau lebih dengan satu variabel dependen. Korelasi dapat dirumuskan sebagai berikut:

$$
r x y=\frac{n\left(\sum x y\right)-\left(\sum x\right) \cdot\left(\sum y\right)}{\sqrt{\left(n \cdot \sum x 2-\left(\sum x 2\right)\left(n \cdot \sum x\right)\right)^{2}\left(n \cdot \sum x^{2}-\left(\sum y\right)^{2}\right)}}
$$

Dimana:

$$
\begin{aligned}
r_{\mathrm{xy}}= & \text { Koefisien korelasi } \\
& \text { antara variabel } \mathrm{X} \text { dan } \mathrm{Y} \\
\mathrm{X}= & \text { Variabel Bebas } \\
\mathrm{y}= & \text { Variabel Terikat } \\
\mathrm{n}= & \text { Jumlah responden atau } \\
& \text { sampel }
\end{aligned}
$$

3. Koefisien Determinasi

Pada model liniear ini, akan terlihat besarnya kontribusi untuk variabel bebas secara bersama-sama dalam mempengaruhi variabel terikat dengan melihat besarnya koefisien determinasi totalnya $\left(\mathrm{R}^{2}\right)$. Jika $\left(\mathrm{R}^{2}\right)$ yang diperoleh mendekati (satu) maka dapat dikatakan semakin kuat model tersebut menerangkan hubungan variabel bebas terhadap variabel terikat. Sebaliknya jika $\left(\mathrm{R}^{2}\right)$ makin mendekati 0 (nol) semakin lemah pengaruh variabelvariabel bebas terhadap variabel terikat.

$$
R=r^{2} \times 100 \%
$$

Dimana:

$\mathrm{R}=$ Koefisien determinasi

$r \quad=$ Koefisien korelasi 
4. Pengujian Hipotesis

$$
\text { Menurut Sugiyono }
$$

(2013:296), bahwa hipotesis adalah dugaan / pernyataan sementara yang diungkapkan secara deklaratif sementara yang menjadi jawaban dari sebuah permasalahan.

1. Uji $F$, digunakan untuk mengetahui apakah masingmasing variabel bebasnya secara bersama-sama berpengaruh secara signifikan terhadap variabel terikat dimana jika sig $>\dot{a}$ (0.05), maka $\mathrm{H}_{0}$ diterima dan $\mathrm{H}_{1}$ ditolak jika sig $<\dot{a}(0,05)$, maka $\mathrm{H}_{0}$ ditolak dan $\mathrm{H}_{1}$ diterima.

2. Uji t, digunakan untuk mengetahui apakah masing- masing variabel bebasnya secara sendiri-sendiri berpengaruh secara signifikan terhadap variabel terikat dimana jika sig $>\dot{a}$ (0.05), maka $\mathrm{H}_{0}$ diterima dan $\mathrm{H}_{1}$ ditolak jika sig< $\dot{a}(0,05)$ maka $\mathrm{H}_{0}$ ditolak dan $\mathrm{H}_{1}$ diterima.

thitung $=\frac{r \sqrt{n-2}}{\sqrt{1-r 2}}$

Dimana :

$\mathrm{T}$ : nilai $\mathrm{t}$

$\mathrm{R}$ : Koefisien Korelasi

$\mathrm{n}$ : Jumlah Data

Sedangkan untuk menentukan nilai digunakan krateria

- Taraf signifikan $\infty 5 \%$

- Derajat kebebasan (dk) =n-2

\section{HASIL DAN PEMBAHASAN Hasil Uji Coba Instrumen Uji Validitas}

Tabel 1

Hasil Uji Validitas Motivasi $\left(\mathbf{X}_{1}\right)$

\begin{tabular}{|l|c|c|c|}
\hline Item Pertanyaan & $\mathbf{r}_{\text {hitung }}$ & $\mathbf{r}_{\text {tabel }}$ & Keterangan \\
\hline Pertanyaan 1 & 0,598 & 0,202 & Valid \\
\hline Pertanyaan 2 & 0,655 & 0,202 & Valid \\
\hline Pertanyaan 3 & 0,469 & 0,202 & Valid \\
\hline Pertanyaan 4 & 0,592 & 0,202 & Valid \\
\hline Pertanyaan 5 & 0,641 & 0,202 & Valid \\
\hline Pertanyaan 6 & 0,643 & 0,202 & Valid \\
\hline Pertanyaan 7 & 0,438 & 0,202 & Valid \\
\hline Pertanyaan 8 & 0,386 & 0,202 & Valid \\
\hline Pertanyaan 9 & 0,516 & 0,202 & Valid \\
\hline Pertanyaan 10 & 0,539 & 0,202 & Valid \\
\hline
\end{tabular}

Sumber: Data diolah 2015

Berdasarkan tabel di atas menunjukkan bahwa variabel motivasi yang digunakan dalam penelitian ini mempunyai $r_{\text {hitung }}$ yang lebih besar dari $r_{\text {table }}$ dari hasil tersebut menunjukkan bahwa variabel motivasi tersebut adalah valid. 
Tabel 2

Hasil Uji Validitas Disiplin Kerja $\left(\mathbf{X}_{2}\right)$

\begin{tabular}{|l|c|c|c|}
\hline Item Pertanyaan & $\boldsymbol{r}_{\text {tabel }}$ & $\boldsymbol{r}_{\text {tabel }}$ & Keterangan \\
\hline Pertanyaan 1 & 0,465 & 0,202 & Valid \\
\hline Pertanyaan 2 & 0,608 & 0,202 & Valid \\
\hline Pertanyaan 3 & 0,545 & 0,202 & Valid \\
\hline Pertanyaan 4 & 0,729 & 0,202 & Valid \\
\hline Pertanyaan 5 & 0,476 & 0,202 & Valid \\
\hline Pertanyaan 6 & 0,549 & 0,202 & Valid \\
\hline Pertanyaan 7 & 0,287 & 0,202 & Valid \\
\hline Pertanyaan 8 & 0,376 & 0,202 & Valid \\
\hline Pertanyaan 9 & 0,436 & 0,202 & Valid \\
\hline Pertanyaan 10 & 0,490 & 0,202 & Valid \\
\hline
\end{tabular}

Sumber: Data diolah 2015

Berdasarkan tabel di atas menunjukkan bahwa variabel disiplin kerja yang digunakan dalam penelitian ini mempunyai $r_{\text {hitung }}$ yang lebih besar dari $r_{\text {table dari hasil tersebut }}$ menunjukkan bahwa variabel disiplin kerja tersebut adalah valid.

Tabel 3

Hasil Uji Validitas Kinerja Pegawai $(Y)$

\begin{tabular}{|l|c|c|c|}
\hline Item Pertanyaan & $\boldsymbol{r}_{\boldsymbol{h i t u n g}}$ & $\boldsymbol{r}_{\text {tabel }}$ & Keterangan \\
\hline Pertanyaan 1 & 0,554 & 0,202 & Valid \\
\hline Pertanyaan 2 & 0,590 & 0,202 & Valid \\
\hline Pertanyaan 3 & 0,568 & 0,202 & Valid \\
\hline Pertanyaan 4 & 0,682 & 0,202 & Valid \\
\hline Pertanyaan 5 & 0,587 & 0,202 & Valid \\
\hline Pertanyaan 6 & 0,610 & 0,202 & Valid \\
\hline Pertanyaan 7 & 0,534 & 0,202 & Valid \\
\hline Pertanyaan 8 & 0,466 & 0,202 & Valid \\
\hline Pertanyaan 9 & 0,562 & 0,202 & Valid \\
\hline Pertanyaan 10 & 0,454 & 0,202 & Valid \\
\hline \multicolumn{2}{|l|}{} \\
\hline
\end{tabular}

Berdasarkan tabel di atas menunjukkan bahwa variabel kinerja pegawai yang digunakan dalam penelitian ini mempunyai $r_{\text {hitung }}$ yang lebih besar dari $r_{\text {table }}$ dari hasil tersebut menunjukkan bahwa variabel kinerja pegawai tersebut adalah valid.

\section{Uji Reliabilitas}

\section{Tabel 4}

Reliabilitas Motivasi $\left(\mathbf{X}_{1}\right)$

\begin{tabular}{|r|r|}
\hline Cronbach's Alpha & N of Items \\
\hline .725 & 10 \\
\hline
\end{tabular}

Sumber: Data diolah 2015

Didapat nilai Cronbach' Alpha sebesar $0,725>0,6$. Karena nilai diatas 0,6 maka dapat disimpulkan bahwa alat ukur dalam penelitian 
reliabel dan dapat dijadikan alat ukur dianalisis selanjutnya.

Tabel 5

Reliabilitas Disiplin Kerja $\left(\mathbf{X}_{2}\right)$

\begin{tabular}{|r|r|}
\hline Cronbach's Alpha & N of Items \\
\hline .795 & 10 \\
\hline
\end{tabular}

Sumber: Data diolah 2015

Didapat nilai Cronbach' Alpha sebesar 0,795 > 0,6. Karena nilai diatas 0,6 maka dapat disimpulkan bahwa alat ukur dalam penelitian reliabel dan dapat dijadikan alat ukur dianalisis selanjutnya.

\section{Tabel 6}

Reliabilitas Kinerja Pegawai (Y) Reliability Statistics

\begin{tabular}{|r|r|}
\hline Cronbach's Alpha & N of Items \\
\hline .754 & 10 \\
\hline Sumber: Data diolah 2015 &
\end{tabular}

Hasil uji reabilitas didapat nilai Cronbach' Alpha sebesar 0,754 > 0,6. Karena nilai diatas 0,06 maka dapat disimpulkan bahwa alat ukur dalam penelitian reliabel dan dapat dijadikan alat ukur dianalisis selanjutnya.

\section{Uji Normalitas}

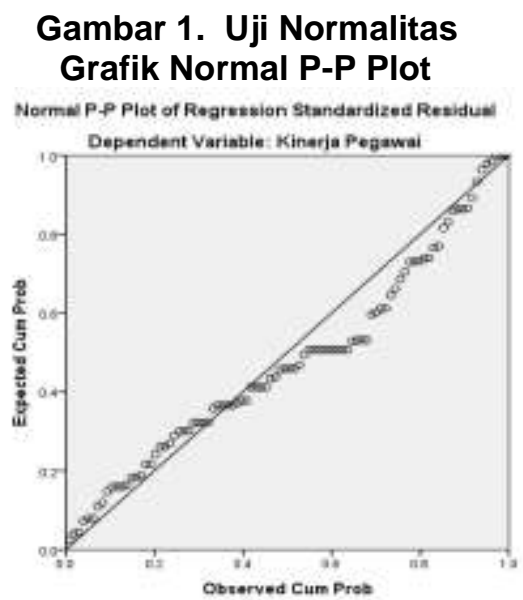

Sumber: Data diolah 2015

Berdasarkan output dapat diketahui bahwa titik-titik menyebar sekitar garis dan mengikuti garis diagonal, maka nilai residual tersebut terdistribusi normal.

\section{Uji Multikolinieritas}

Tabel 7

Uji Multikolinieritas

Coefficients $^{\mathrm{a}}$

\begin{tabular}{|c|c|c|c|c|c|c|c|c|}
\hline \multirow{2}{*}{\multicolumn{2}{|c|}{ Model }} & \multicolumn{2}{|c|}{$\begin{array}{l}\text { Unstandardized } \\
\text { Coefficients }\end{array}$} & \multirow{2}{*}{$\begin{array}{c}\begin{array}{c}\text { Standardize } \\
\mathrm{d}\end{array} \\
\text { Coefficients } \\
\text { Beta }\end{array}$} & \multirow[b]{2}{*}{$\mathrm{T}$} & \multirow[b]{2}{*}{ Sig. } & \multicolumn{2}{|c|}{ Collinearity Statistics } \\
\hline & & $\mathrm{B}$ & Std. Error & & & & Tolerance & VIF \\
\hline \multirow[t]{3}{*}{1} & (Constant) & 16.114 & 4.610 & & 3.495 & .001 & & \\
\hline & Motivasi & .302 & .111 & .279 & 2.714 & .008 & .768 & 1.302 \\
\hline & Disiplin kerja & .294 & .121 & .259 & 2.426 & .017 & .768 & 1.302 \\
\hline
\end{tabular}

a. Dependent Variable: Kinerja Pegawai

Sumber: Data diolah 2015

Dari output diketahui bahwa nila Tolerance kedua variabel lebih dari 0,10 dan VIF kurang dari 10, maka dapat disimpulkan tidak terjadi multikolinieritas antara variabel bebas. 


\section{Uji Heteroskedastisitas}

\section{Gambar 2. Uji Heteroskedastisitas}

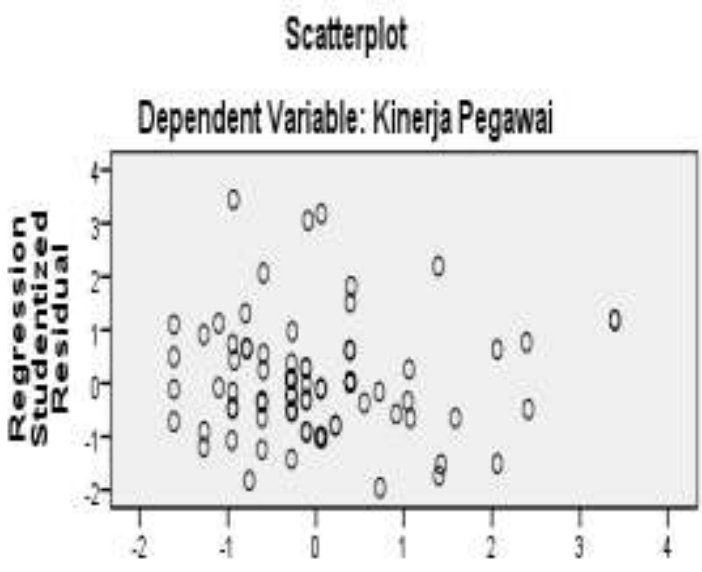

Regression Standardized Predicted Value
Hasil uji heterokesdasitas grafik tidak ada pola yang jelas, seperti titiktitik menyebar diatas dan dibawah angka 0 pada sumbu $Y$, maka disimpulkan tidak terdapat gejala heteroskedasitasitas dalam model regresi yang digunakan.

Tabel 8

Hasil Regresi Linier Sederhana

\begin{tabular}{|c|c|c|c|c|c|c|}
\hline \multicolumn{7}{|c|}{ Coefficients $^{a}$} \\
\hline \multirow{2}{*}{\multicolumn{2}{|c|}{ Model }} & \multicolumn{2}{|c|}{ Unstandardized Coefficients } & $\begin{array}{c}\text { Standardized } \\
\text { Coefficients }\end{array}$ & \multirow[b]{2}{*}{$\mathrm{t}$} & \multirow[b]{2}{*}{ Sig. } \\
\hline & & $\mathrm{B}$ & Std. Error & Beta & & \\
\hline 1 & (Constant) & 22.261 & 3.955 & & 5.629 & .000 \\
\hline & Motivasi & .432 & .100 & .414 & 4.314 & .000 \\
\hline
\end{tabular}

a. Dependent Variable: Kinerja Pegawai

Sumber: Data diolah 2015

Dari hasil perhitungan dapat diketahui persamaan regresi liniear sederhana antara variabel motivasi terhadap kinerja pegawai adalah: $\mathbf{Y}^{\prime}=$ 22,261 + 0,432X. Berdasarkan perhitungan regresi di atas di peroleh konstanta atau sebesar 22,261 dan nilai regresi sebesar 0,432 artinya bahwa ada pengaruh yang positif antara variabel motivasi terhadap kinerja pegawai pada Dinas Koperasi Usaha Kecil dan Menengah (UKM) Provinsi Sumatera Selatan.

Tabel 9.

Hasil Regresi Linier Sederhana

Coefficients $^{\mathrm{a}}$

\begin{tabular}{|c|c|c|c|c|c|c|}
\hline \multirow{2}{*}{\multicolumn{2}{|c|}{ Model }} & \multicolumn{2}{|c|}{ Unstandardized Coefficients } & $\begin{array}{c}\text { Standardized } \\
\text { Coefficients } \\
\end{array}$ & \multirow[b]{2}{*}{$\mathrm{t}$} & \multirow[b]{2}{*}{ Sig. } \\
\hline & & $\mathrm{B}$ & Std. Error & Beta & & \\
\hline 1 & (Constant) & 21.927 & 4.224 & & 5.190 & .000 \\
\hline & Disiplin pegawai & .452 & .110 & .398 & 4.116 & .000 \\
\hline
\end{tabular}

a. Dependent Variable: Kinerja Pegawai

Sumber: Data diolah 2015 
Dari hasil perhitungan dapat diketahui persamaan regresi liniear sederhana antara variabel disiplin pegawai terhadap kinerja pegawai adalah $Y^{\prime}=21,927+0,452 X$. Berdasarkan perhitungan regresi di atas di peroleh konstanta atau sebesar
21,927 dan nilai regresi sebesar 0,452 artinya bahwa ada pengaruh yang positif antara variabel disiplin pegawai terhadap kinerja pegawai pada Dinas Koperasi Usaha Kecil dan Menengah (UKM) Provinsi Sumatera Selatan.

Tabel 10

Hasil Regresi Linier Berganda

Coefficients

\begin{tabular}{|c|c|c|c|c|c|c|}
\hline \multirow{2}{*}{\multicolumn{2}{|c|}{ Model }} & \multicolumn{2}{|c|}{ Unstandardized Coefficients } & $\begin{array}{l}\text { Standardized } \\
\text { Coefficients }\end{array}$ & \multirow[b]{2}{*}{$\mathrm{t}$} & \multirow[b]{2}{*}{ Sig. } \\
\hline & & $\mathrm{B}$ & Std. Error & Beta & & \\
\hline \multirow[t]{3}{*}{1} & (Constant) & 16.114 & 4.610 & & 3.495 & .001 \\
\hline & Motivasi & .302 & .111 & .289 & 2.714 & .008 \\
\hline & Disiplin kerja & .294 & .121 & .259 & 2.426 & .017 \\
\hline
\end{tabular}

a. Dependent Variable: Kinerja Pegawai

Sumber: Data diolah

Sumber: Data diolah 2015

Berdasarkan nilai tersebut diperoleh persamaan regresi linier berganda adalah:

\section{$Y^{\prime}=16,114+0,302 X_{1}+0,294 X_{2}$}

Konstanta 16,114 artinya jika motivasi $\left(\mathrm{X}_{1}\right)$ nilainya 0 , dan disiplin kerja $\left(\mathrm{X}_{2}\right)$ nilainya 0 , maka kinerja pegawai $(\mathrm{Y})$ nilainya sebesar 16,114 . Sedangkan koefisien regresi variabel motivasi $\left(\mathrm{X}_{1}\right)$ sebesar 0,302 artinya jika motivasi mengalami kenaikan satu satuan, maka kinerja pegawai mengalami peningkatan sebesar 0,302 satuan asumsi variabel independen lainya bernilai tetap. Dan koefisien disiplin kerja $\left(X_{2}\right)$ sebesar 0,294 artinya jika disiplin kerja mengalami kenaikan satu-satuan, maka kinerja pegawai akan mengalami peningkatan sebesar 0,294 satuan dengan asumsi variabel independen lainya bernilai tetap.

Tabel 11.

Uji t (Parsial)

Coefficients $^{\mathrm{a}}$

\begin{tabular}{|c|c|c|c|c|c|c|}
\hline \multirow{2}{*}{\multicolumn{2}{|c|}{ Model }} & \multicolumn{2}{|c|}{$\begin{array}{c}\text { Unstandardized } \\
\text { Coefficients }\end{array}$} & \multirow{2}{*}{$\begin{array}{c}\begin{array}{c}\text { Standardized } \\
\text { Coefficients }\end{array} \\
\text { Beta }\end{array}$} & \multirow[b]{2}{*}{$\mathrm{t}$} & \multirow[b]{2}{*}{ Sig. } \\
\hline & & $B$ & Std. Error & & & \\
\hline \multirow[t]{3}{*}{1} & (Constant) & 16.114 & 4.610 & & 3.495 & .001 \\
\hline & Motivasi & .302 & .111 & .289 & 2.714 & .008 \\
\hline & Disiplin kerja & .294 & .121 & .259 & 2.426 & .017 \\
\hline
\end{tabular}

a. Dependent Variable: Kinerja Pegawai

Sumber: Data diolah 2015

Uji t (parsial) untuk menguji pengaruh tiap variabel independen secara sendiri-sendiri (parsial) terhadap variabel dependen dengan membandingkan nilai $t_{\text {hitung }}$ dengan $t_{\text {tabel}}$, jika $t_{\text {hitung }}<t_{\text {tabel }}$ maka variabel tersebut tidak berpengaruh secara signifikan.

Nilai tabel $\mathrm{n}=92-2=90$ sampel dan alpha 0,05 adalah 1,994, Sehingga uji $\mathrm{t}$ sesuai tabel diatas adalah : 
1. $X_{1}=t_{\text {hitung }} 2,714$ sehingga $>t_{\text {tabel }}$ 1,994, artinya variabel motivasi secara parsial berpengaruh secara signifikan terhadap variabel kinerja pegawai.
2. $\mathrm{X}_{2}=\mathrm{t}_{\text {hitung }} 2,426>\mathrm{t}_{\text {tabel }} 1,994$, artinya bahwa variabel disiplin kerja secara parsial berpengaruh terhadap variabel kinerja pegawai.

Tabel 12.

Uji F (bersama-sama)

ANOVA $^{a}$

\begin{tabular}{|ll|r|r|r|r|r|}
\hline \multicolumn{1}{|l|}{} & \multicolumn{1}{c|}{$\begin{array}{c}\text { Sum of } \\
\text { Model }\end{array}$} & Squares & Df & Mean Square & F & Sig. \\
\hline 1 & Regression & 289.393 & 2 & 144.697 & 12.752 & $.000^{\mathrm{b}}$ \\
& Residual & 1009.857 & 89 & 11.347 & & \\
& Total & 1299.250 & 91 & & & \\
\hline
\end{tabular}

a. Dependent Variable: Kinerja Pegawai

b. Predictors: (Constant), Motivasi, Disiplin kerja

Sumber: Data diolah 2015

Uji $F$ secara simultan untuk mengetahui pengaruh seluruh variabel independen terhadap variabel dependen secara bersama-sama (simultan), jika nalai $F_{\text {hitung }}>F_{\text {tabel }}$ maka secara bersama-sama seluruh variabel independen berpengaruh terhadap variabel dependen. Metode lain juga dapat dilakukan dengan melihat angka signifikansi (sig), jika angka sig < 0,05 maka berpengaruh, dan jika angka sig $>0,05$ maka tidak berpengaruh. Hasil pengujian menunjukkan angka sig 0,000 sehingga $<0,05$, sehingga dapat dikatakan variabel independen secara bersama-sama berpengaruh terhadap variabel dependen.

Tabel 13.

\section{Koefisien Determinan}

\begin{tabular}{|l|r|r|r|r|}
\multicolumn{5}{|c|}{ Model Summary } \\
\hline Model & $\mathrm{R}$ & $\mathrm{R}$ Square & \multicolumn{1}{c|}{$\begin{array}{c}\text { Adjusted R } \\
\text { Square }\end{array}$} & $\begin{array}{c}\text { Std. Error of the } \\
\text { Estimate }\end{array}$ \\
\hline 1 & $.472^{\mathrm{a}}$ & .223 & .205 & 3.368 \\
\hline
\end{tabular}

a. Predictors: (Constant), Motivasi, Disiplin pegawai

Sumber: Data diolah 2015

Berdasarkan tabel diatas maka pengaruh yang diberikan oleh motivasi dan disiplin kerja terhadap kinerja pegawai dapat dijelaskan oleh test determinant $\left(R_{\text {squaer }}\right.$ atau $R^{2}$ ) sebesar 0,223 atau $22,3 \%$, sehingga dalam penelitian ini motivasi dan disiplin kerja dapat mempengaruhi kinerja pegawai sebesar $22,3 \%$. Untuk masing-masing variabel motivasi dan disiplin kerja sedangkan sisanya $77,7 \%$ dipengaruhi oleh variabel lain.

\section{Pengujian Hipotesis}

Setelah diperoleh hasil perhitungan regresi liniear sederhana dan koefisiean korelasi antara motivasi dan disiplin kerja terhadap kinerja pegawai, maka dilakukan uji hipotesis dengan langkah-langkah sebagai berikut :

a. Menyusun formulasi $\mathrm{Ho}$ dan $\mathrm{Ha}$

Berdasarkan hipotesis yang sudah dikemukakan sebelumnya, bahwa terdapat pengaruh motivasi dan disiplin kerja 
terhadap kinerja pegawai pada Dinas Koperasi Usaha Kecil dan Menengah (UKM) Provinsi Sumatera Selatan. Dari hipotesis tersebut akan di formulasikan hipotesis (Ho) dan hipotesis alternative $(\mathrm{Ha})$ sebagai berikut :

$\mathrm{Ha}_{1}$ : Motivasi dan disiplin kerja berpengaruh terhadap kinerja pegawai pada Dinas Koperasi Usaha Kecil dan Menengah (UKM) Provinsi Sumatera Selatan.

$\mathrm{Ho}_{1}$ : Motivasi dan disiplin kerja tidak berpengaruh terhadap kinerja pegawai pada Dinas Koperasi Usaha Kecil dan Menengah

Provinsi (UKM) Selatan

b. Menentukan $t_{\text {hitung }}$ dan nilai signifikansi

Dari output di dapat $t_{\text {hitung }}$ sebesar 2,714 dan signifikansi 0,008

c. Menentukan $t_{\text {tabel }}$ $t_{\text {tabel }}$ dapat dilihat pada tabel statistik pada signifikan 0,05 dengan derajat kebebasan $\mathrm{df}=$ $\mathrm{n}-\mathrm{k}$ atau 92-2 = 90, hasil diperoleh untuk tabel sebesar 1,662 (lihat pada lampiran $t$ tabel)

d. Kriteria pengujian

Jika $-t_{\text {tabel }} \leq t_{\text {hitung }} \leq t_{\text {tabel }}$ maka Ho diterima

Jika $t_{\text {hitung }}<t_{\text {tabel }}$ atau $t_{\text {hitung }}>t_{\text {tabel }}$ maka Ho ditolak

Berdasarkan signifikansi :

Jika signifikansi > 0,05 maka Ho diterima.

Jika signifikansi $<0,05$ maka Ho ditolak.

e. Membuat kesimpulan

Nilai $t_{\text {hitung }}>t_{\text {tabel }}(2,714>1,662)$ dan signifikansi $<0,05(0,008<$ $0,05)$ maka Ho ditolak, jadi dapat disimpulkan bahwa motivasi secara parsial berpengaruh terhadap kinerja pegawai. Nilai $t$ hitung positif artinya berpengaruh positif, yaitu jika motivasi meningkat, maka kinerja pegawai juga meningkat di Dinas Koperasi Usaha Kecil Dan Menengah (UKM) Provinsi Sumatera Selatan

\section{Pembahasan}

Dari hasil uji validitas output dapat diketahui nilai korelasi antara skor total item motivasi, skor total disiplin kerja, dan skor item kinerja pegawai. Nilai ini bandingkan dengan $r_{\text {tabel }}$ dapat dicari pada signifikan 0,05 dengan uji dua sisi dan jumlah responden $n=92$ maka didapat $r_{\text {tabel }}$ sebesar 0,205 dapat disimpulkan bahwa dari item pertanyaan variabel motivasi $\left(\mathrm{X}_{1}\right)$, disiplin kerja $\left(\mathrm{X}_{2}\right)$, dan kinerja pegawai $(Y)$ dinyatakan valid semua karena $r_{\text {hitung }}>r_{\text {tabel. }}$. Hasil uji reliabilitas dapat dilihat pada output reliabilitas statistik motivasi dan disiplin kerja dengan Cronbach'Alpha sebesar 0,725 dan 0,663 karena nilai diatas 0,6 maka disimpulkan kinerja pegawai dengan Crobach'Alpha sebesar 0,747 karena nilai diatas 0,6 maka dapat disimpulkan bahwa seluruh item pertanyaan kinerja pegawai dapat dinyatakan reliabel. Maka dapat diketahui persamaan regresi linier sederhana antara variabel motivasi terhadap kinerja pegawai adalah $Y^{\prime}=\mathbf{2 2 , 2 6 1}+\mathbf{0 , 4 3 2 X}$

Dan persamaan regresi linier sederhana antara variabel disiplin kerja terhadap kinerja pegawai adalah $\mathbf{Y}^{\prime}=$

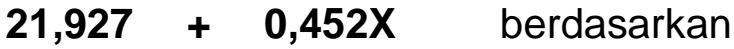
perhitungan regresi di atas di peroleh konstanta atau sebesar 21,927 dan nilai regresi sebesar 0,452 artinya bahwa ada pengaruh yang positif antara variabel disiplin kerja terhadap kinerja pegawai pada Dinas Koperasi Usaha Kecil dan Menengah (UKM) Provinsi Sumatera Selatan. 
Berdasarkan hasil regresi liniear berganda diperoleh nilai koefisien regresi untuk motivasi sebesar 0,302 dan nilai koefisien regresi untuk disiplin pegawai sebesar 0,294, dan koefisien konstanta sebesar 16,114. Berdasarkan nilai tersebut diperoleh persamaan regresi linier berganda adalah $Y^{\prime}=16,114+0,302 X_{1}+$ I0,2\$SIMPULAN DAN SARAN

Untuk memperkuat hasil pengaruh yang telah diketahui tadi, dapat pula dilakukan dengan melihat kuat tidaknya hubungan antara variabel motivasi dan disiplin kerja terhadap kinerja pegawai, maka dapat tingkat hubungan adalah:

Tabel 14 Tingkat Hubungan

\begin{tabular}{|c|c|c|}
\hline No & $\begin{array}{c}\text { Interval } \\
\text { Koefisien }\end{array}$ & $\begin{array}{c}\text { Tingkat } \\
\text { Hubungan }\end{array}$ \\
\hline $\mathbf{1}$ & $0,00-0,19$ & Sangat Rendah \\
\hline $\mathbf{2}$ & $0,20-0,39$ & Rendah \\
\hline $\mathbf{3}$ & $0,40-0,59$ & Sedang \\
\hline $\mathbf{4}$ & $0,60-079$ & Kuat \\
\hline $\mathbf{5}$ & $0,80-1,00$ & Sangat Kuat \\
\hline
\end{tabular}

Berdasarkan

perhitungan dengan menggunakan tabel maka koefisien korelasi ( $r$ ) diperoleh nilai sebesar 4,72 maka dalam hal ini berarti menujukkan hubungan antara motivasi dan disiplin pegawai terhadap kinerja pegawai bertingkat sedang.

Uji $F$ secara bersama-sama (simultan) adalah untuk mengetahui pengaruh seluruh variabel independen terhadap variabel dependen secara simultan (bersama-sama), jika nilai $\mathrm{F}_{\text {hitung }}>\mathrm{F}_{\text {tabel }}$ maka secara bersamasama (simultan) seluruh variabel independen berpengaruh terhadap variabel independen.

Metode lain juga dapat dilakukan dengan melihat angka signifikansi (sig), jika angka sig $<0,05$ maka berpengaruh, jika sig $>0.05$ maka tidak berpengaruh. Hasil pengujian menunjukan angka sig 0,000 sehingga < 0,05 sehingga kesimpulannya variabel independen secara bersama-sama berpengaruh terhadap variabel dependen baik pada Dinas Koperasi Usaha Kecil Dan Menengah (UKM) Provinsi Sumatera Selatan

\section{SIMPULAN DAN SARAN}

\section{Kesimpulan}

1. Secara parsial motivasi berpengaruh signifikan terhadap kinerja pegawai.

2. secara parsial juga disiplin kerja berpengaruh terhadap kinerja pegawai.

3. secara bersama-sama (simultan) motivasi dan disiplin kerja berpengaruh signifikan terhadap kinerja pegawai.

\section{Saran}

Sehubungan dengan kesimpulan diatas yang telah diuraikan, maka penulis memberikan saran sebagai bahan masukan bagi Dinas Koperasi Usaha Kecil dan Menengah (UKM) Provinsi Sumatera Selatan yang penulis ajukan berkaitan dengan penelitian, mudah-mudahan dapat diambil manfaatnya oleh instansi dan dapat menambah wawasan bagi mereka yang membacanya.

1. Sebaiknya pihak organisasi meningkatkan pengelolahan SDM yang dimiliki agar kinerja pegawai meningkat. Misalnya meperhatikan kinerja pegawai.

2. Diharapkan dapat memberikan kinerja pegawai yang nyaman sehingga pegawai merasakan kepuasan dalam bekerja untuk mencapai tujuan organisasi.

3. Untuk penelitian yang akan datang hendakanya meneliti tentang variabel lain. 
4. Diharapkan kepala dinas lebih lagi meningkatkan pengawasan terhadap bawahannya demi tercapainya tujuan organisasi.

\section{DAFTAR PUSTAKA}

Hasibuan, 2011, Manajemen Sumber Daya Manusia, Bumi Aksara, Jakarta.

Hendi dan Angara, 2010, Manajemen Personalia, edisi ke tiga, Gadjah Mada, Yogyakarta.

Kaswan, 2012, Manajemen Sumber Daya Manusia Untuk Keunggulan

BersaingOrganisasi, Graha Ilmu, Yogyakarta.

Manullang, 2011, Manajemen Personalia, Gadjah Mada University Press, Yogyakarta.

Priyatno, 2014, SPSS 22 Pengolahan Data Terpraktis, Penerbit ANDI, Yogyakarta.

Rivai, Verzha 2009, Manajemen Sumber Daya Manusia Untuk Perusahaan dari teori dan praktek, PT. Raja Grafindo, Jakarta.

Sjafri, Mangkuprawira, 2011, manajemen sumber daya manusia, edisi ke-2 penerbit Ghalia Indonesia, Bogor.

Sondang, Sigian 2013, Manajemen Sumber Daya Manusia, Penerbit Bumi Aksara, Jakarta.

Soekidjo, Notoatmodjo, 2009, Pengembangan Sumber Daya Manusia, PT. Rineka Cipta, Jakarta.

Sugiyono, 2013, Metode Penelitian Bisnis (MPB), Penerbit Alfabeta, Bandung.

Suprihanto, John 2003, Manajemen Sumber Daya Manusia, BPFE, Yogyakarta.

Suwatno, dan Priansa, 2011, Manajemen Sumber Daya Manusia, Penerbit Alfabeta, Bandung.
Sujarweni, V Wiratna, 2014, SPSS Untuk Penelitian, Cetakan Pertama, Pustaka Baru Press, Yogyakarta.

Sunyoto, Danang 2013, Sumber Daya Manusia: Teori, Kuisoner, Dan Analisis Data, Penerbit Caps (Center For Academic Publishing Service), Yogyakarta.

Sumber $\begin{array}{r}\text { Daya } \\ \text { cetatakan kedua, }\end{array}$
CAPS, Jakarta.

Sedarmayanti, 2007, Tata Kerja dan produktivitas kerja, Penerbit Mandar Maju, Bandung.

Wibowo, 2010, Manajemen Sumber Daya Manusia, Alfabeta, Bandung.

Wilson, Bangun 2012, Manajemen Sumber Daya Manusia, Penerbit Erlangga, Jakarta. 